\title{
The combination of anti-HBc and anti-HBs levels is a useful predictor of the development of chemotherapy-induced reactivation in lymphoma patients with resolved HBV infection
}

\author{
TOKUHIRO MATSUBARA, TSUTOMU NISHIDA, AKIYOSHI SHIMODA, HIROMI SHIMAKOSHI, \\ TAKAHIRO AMANO, AYA SUGIMOTO, KEI TAKAHASHI, KAORI MUKAI, MASASHI YAMAMOTO, \\ SHIRO HAYASHI, SACHIKO NAKAJIMA, KOJI FUKUI and MASAMI INADA
}

Department of Gastroenterology and Hepatology, Toyonaka Municipal Hospital, Toyonaka, Osaka 560-8565, Japan

Received May 25, 2017; Accepted September 12, 2017

DOI: $10.3892 / \mathrm{ol} .2017 .7012$

\begin{abstract}
Fatal chemotherapy-induced hepatitis B virus reactivation (HBV-R) is a well-described serious complication observed in patients with lymphoma and resolved HBV infection. The aim of the present study was to determine the predictive factors of the development of chemotherapy-induced HBV-R. A total of 77 consecutive newly diagnosed patients with lymphoma and resolved HBV infection, who received chemotherapy from 2007 through 2015 were analysed retrospectively. Significant predictive factors associated with HBV-R were identified based on the data from these patients. Ten patients developed HBV-R during and following chemotherapy, and two of these 10 patients developed HBV-associated hepatitis flares. There was a significant negative correlation between anti-hepatitis $B$ core $(\mathrm{HBc})$ titres prior to chemotherapy and time to HBV-R $(\mathrm{P}=0.016$, $\mathrm{R}=-0.732$ ). Univariate and multivariate logistic regression analyses demonstrated that anti-HBc and anti-hepatitis B surface (HBs) titres at baseline were significant predictive factors for HBV-R. In addition, patients with high anti-HBc titres at baseline (above $10 \mathrm{~S} / \mathrm{CO}$ ) were significantly more likely to experience HBV-R than patients with low anti-HBc and high anti-HBs titres (above $28 \mathrm{mIU} / \mathrm{ml}$ ), who did not experience complete reactivation $(\mathrm{P}<0.0001)$. Furthermore, patients with low anti-HBs titres were significantly more likely to experience HBV-R than those with high anti-HBs titres $(\mathrm{P}=0.031)$. All HBV-R episodes among the patients with high anti-HBc titres occurred within 3 months following the
\end{abstract}

Correspondence to: Dr Tokuhiro Matsubara, Department of Gastroenterology and Hepatology, Toyonaka Municipal Hospital, 4-14-1 Shibahara, Toyonaka, Osaka 560-8565, Japan

E-mail: tmatsubara@chp.toyonaka.osaka.jp

Abbreviations: HBV, hepatitis B virus; $\mathrm{HBV}-\mathrm{R}, \mathrm{HBV}$ reactivation

Key words: hepatitis B, reactivation, chemotherapy, lymphoma, predictor initiation of chemotherapy. The combination of anti-HBc and anti-HBs titres, as opposed to either titre alone, at baseline in patients with lymphoma may serve as a surrogate marker for the occurrence of HBV-R under the influence of chemotherapy.

\section{Introduction}

Hepatitis B virus (HBV) reactivation and hepatitis flares are well-recognized complications that occur in cancer patients who have undergone cytotoxic chemotherapy. HBV reactivation (HBV-R) is most often reported in patients with haematologic malignancies, particularly patients with lymphoma who have been treated with rituximab. The incidence of HBV-R has been reported to range from 4.1 to $23.8 \%$, even in lymphoma patients with resolved HBV infection, who, from a clinical standpoint, are considered to have recovered from HBV infection (1-5). The clinical spectrum of HBV-R in this population varies from self-limited or asymptomatic hepatitis to fulminant hepatitis. HBV-R occasionally leads to hepatitis-related death (4). In particular, the combination regimen of rituximab and cytotoxic chemotherapy, which is the standard regimen for patients with diffuse large B-cell lymphoma and follicular lymphoma, has been found to increase the risk of HBV-R and hepatitis flares in patients with resolved HBV infection $(3,6)$.

In addition to rituximab use, other potential factors, including advanced age and male sex, have been reported to be associated with HBV-R $(3,7,8)$. Recently, a relationship between antibodies to hepatitis B surface antigen (anti-HBs) and HBV-R was reported. However, to our knowledge, no important pre-therapy predictive markers of HBV-R timing and development have been reported. Thus, it remains unclear how HBV-R may be identified prior to chemotherapy in lymphoma patients with resolved HBV infection. Additionally, there are limited clinical data on patients with resolved HBV infection, and there is no established standard surveillance method for monitoring patients with resolved HBV to prevent HBV-R.

Several reports have demonstrated the importance of monitoring of HBV DNA to detect HBV-R occurrence in 
patients with resolved HBV infection. These reports have indicated that such patients should be closely monitored with HBV DNA and serum biochemistry studies for at least 6 months after completion of therapy and that antivirals should be administered promptly upon detection of reactivation $(9,10)$. However, no previous studies of cancer patients with resolved HBV infection were able to devise unified methods of diagnosing HBV-R, nor were these studies able to determine appropriate follow-up intervals for monitoring patients with different tumour types who were receiving chemotherapy regimens of different intensities during and after chemotherapy. Generally, the incidence of HBV-R in outpatients is low (11), and HBV monitoring is expensive. Additionally, clinical evidence alone is insufficient for determining the optimal frequency and duration of HBV DNA monitoring during and after chemotherapy.

Therefore, this retrospective study sought to clarify the predictive factors for chemotherapy-induced HBV-R in lymphoma patients with resolved HBV infection who were undergoing standard chemotherapy.

\section{Materials and methods}

Patients. This was a single-centre retrospective study. A total of four hundred twenty-nine consecutive patients with newly diagnosed, histologically proven lymphoma who were treated at Toyonaka Municipal Hospital from January 2007 to December 2015 were enrolled in the study. Of these 429 patients, 393 patients underwent chemotherapy. The remaining 36 patients did not undergo chemotherapy due to poor performance status or because they received another form of treatment for their disease. Regarding HBV serological markers, 17 patients were positive for hepatitis B surface antigen (HBsAg) (4.0\%), and 412 patients were negative for HBsAg (96.0\%). Of the HBsAg-negative patients, 173 were negative for both antibodies to hepatitis B core antigen (anti-HBc) and anti-HBs, and 122 (28\%) were untested for anti-HBc and/or anti-HBs because we did not always check for these markers prior to the publication and introduction into practice of the Hepatitis B Treatment Guidelines of the Japan Society of Hepatology in 2011 (12). Four patients were positive for antibodies against hepatitis $\mathrm{C}$ virus. Resolved hepatitis B was defined as HBsAg seronegativity and anti-HBs seropositivity and/or having anti-HBc, but 6 patients with anti-HBs seropositivity and anti-HBc seronegativity had not been previously vaccinated against HBV. Fifty-five patients (71\%) enrolled in this study were tested for HBV DNA prior to chemotherapy, and they were negative; however, the other patients were not tested. We excluded 352 patients; therefore, a total of 77 patients (17.9\%) with resolved hepatitis B who received chemotherapy were ultimately analysed in the study (Fig. 1). This study conformed to the Declaration of Helsinki and local legislation and was approved by the Ethics Committee of Toyonaka Municipal Hospital in 2015.

$H B V$-related marker measurements. Serum HBV viral loads were quantified using reverse transcription- quantitative polymerase chain reaction (TaqMan ${ }^{\circledR}$ HBV Test; Roche Diagnostics Japan, Tokyo, Japan), with a minimal sensitivity of $2.1 \mathrm{log}$ copies $/ \mathrm{ml}$, and all serum HBsAg, anti-HBc and

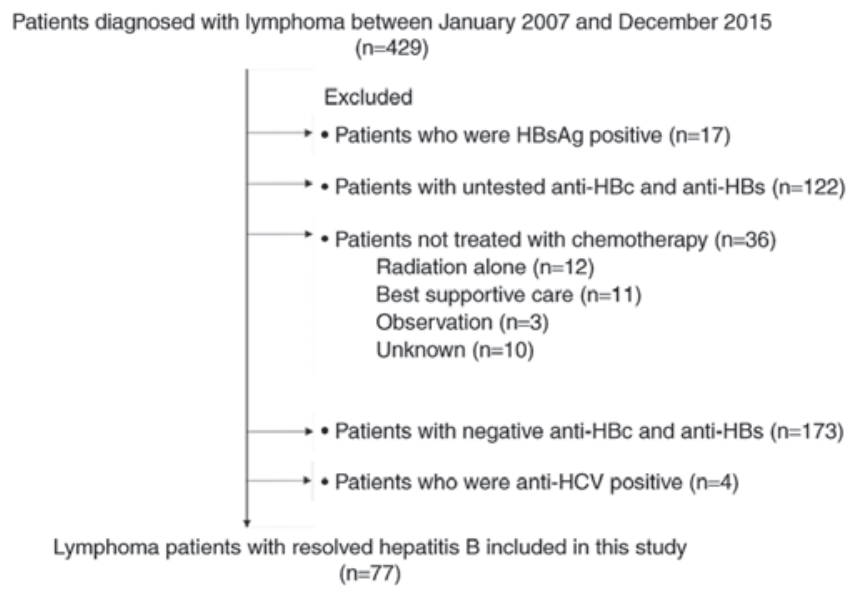

Figure 1. Flow chart of patient selection. HBs, hepatitis B surface; HBc, hepatitis B core; $\mathrm{HCV}$, hepatitis $\mathrm{C}$ virus.

anti-HBs levels were evaluated using the same commercially available enzyme immunoassays with minimum sensitivities of $0.05 \mathrm{IU} / \mathrm{ml}, 1 \mathrm{~S} / \mathrm{CO}$ and $10 \mathrm{mIU} / \mathrm{ml}$, respectively, via CLIA (Architect ${ }^{\mathrm{R}}$; Abbott Japan, Chiba, Japan). The intra-assay and total (inter- and intra-assay) variation (\% coefficient of variation) of anti-HBc levels in this study were evaluated and reported as 2.5 to $6.5 \%$ and 2.8 to $7.5 \%$, respectively (Architect ${ }^{\circledR}$; Abbott Japan; www.ilexmedical.com/files/PDF/AntiHBc_ARC.pdf). Additionally, anti-HBc and anti-HBs levels were measured only prior to treatment according to the guidelines (12).

Definitions of hepatitis flare and $\mathrm{HBV}$ reactivation. $\mathrm{HBV}$ reactivation (HBV-R) was defined according to the Hepatitis B Treatment Guidelines of the Japan Society of Hepatology (12), and HBV-R was defined as a detectable elevated HBV viral load or as HBsAg reverse-seroconversion in patients with resolved hepatitis B during or after chemotherapy. Hepatitis flare was defined as a 3 -fold or greater increase in alanine aminotransferase (ALT) to a level exceeding the upper limit of normal (ULN) (40 U/l) in patients with HBV-R. As previously reported, delayed HBV-R was defined as HBV-R more than 3 months after completing chemotherapy $(1,7)$.

Chemotherapy for lymphoma and treatment for HBV-R. Lymphoma treatment was based on the guidelines of the Japan Society of Hematology. The details of the chemotherapy regimens are presented in Table I. Patients with resolved HBV infection who experienced HBV-R were orally administered $0.5-1 \mathrm{mg}$ of entecavir daily.

Outcomes and follow-up. The primary endpoint was the incidence of HBV-R during or after chemotherapy in lymphoma patients with resolved HBV. Time to HBV-R was calculated as the elapsed time from the day of chemotherapy initiation to the day of HBV-R detection. Delayed HBV-R was defined as HBV-R more than 3 months after completing chemotherapy. All enrolled patients were evaluated at least once every chemotherapy cycle and underwent liver function and HBV viral load testing every one to three months. After the patients completed chemotherapy, their HBV viral loads were followed for at least for 12 months. The follow-up observation period 
Table I. Baseline characteristics of lymphoma patients with resolved HBV infection who were treated with chemotherapy.

\begin{tabular}{lc}
\hline Characteristics & $\begin{array}{c}\text { Number of } \\
\text { patients }(\mathrm{n}=77)\end{array}$ \\
\hline Age, years & $75(47-89)$ \\
Sex, male & $46(59.7)$ \\
Haematologic diagnosis & \\
Diffuse large B cell lymphoma & $53(68.8)$ \\
Follicular lymphoma & $9(11.7)$ \\
Mantle-cell lymphoma & $4(5.2)$ \\
Angioimmunoblastic T-cell lymphoma & $3(3.9)$ \\
MALT lymphoma & $2(2.6)$ \\
Burkitt lymphoma & $1(1.3)$ \\
Lymphoplasmacytic lymphoma & $1(1.3)$ \\
Other & $4(5.2)$ \\
Viral serology & \\
Anti-HBc seropositive & $71(92.2)$ \\
Anti-HBs seropositive & $58(75.3)$ \\
Blood biochemical findings & \\
Baseline ALT, U/l & $17.5 \pm 8.5$ \\
Baseline albumin, g/l & $3.3 \pm 0.8$ \\
Baseline total bilirubin, mg/dl & $0.8 \pm 0.5$ \\
Treatment regimens & $68(88.3)$ \\
Rituximab-containing chemotherapy & \\
CHOP-based chemotherapy & \\
Otherc & \\
Duration of follow-up, days & $(3.9)$ \\
\hline
\end{tabular}

Data are expressed as $\mathrm{n}(\%)$ or as the mean (range). anti-HBc, anti-hepatitis B core antibody; anti-HBs, anti-hepatitis B surface antibody; ALT, alanine aminotransferase; CHOP, cyclophosphamide + hydroxydaunorubicin + vincristine $\left(\right.$ Oncovin $\left.{ }^{\circledR}\right)+$ prednisolone. ${ }^{\text {aPatients with }}$ CD20-positive lymphoma were administered rituximab-containing chemotherapy comprising rituximab with cyclophosphamide, hydroxydaunorubicin, vincristine and prednisolone (R-CHOP); rituximab with tetrahydropyranyl adriamycin, cyclophosphamide, vincristine and prednisolone (R-THP-COP); or rituximab with dose-adjusted etoposide, prednisolone, vincristine, cyclophosphamide and hydroxydaunorubicin (DA-EPOCH-R). 'Patients with CD20-negative lymphoma received cyclophosphamide, hydroxydaunorubicin, vincristine and prednisolone $(\mathrm{CHOP})$ or fludarabine, hydroxydaunorubicin, vincristine and prednisolone. Patients with Hodgkin lymphoma received adriamycin, bleomycin, vinblastine and dacarbazine (ABVd).

was measured from the day of chemotherapy initiation to the date of the last visit or the date of death during the study period.

Statistical analysis. Correlations between two groups were assessed via Pearson's analysis, and multiple comparisons among more than two groups were assessed via the Kruskal-Wallis non-parametric test. HBV reactivation-free survival rates in patients with lymphoma who underwent chemotherapy were estimated by the Kaplan-Meier method, and the log-rank test was used for comparisons. Receiver operating characteristic (ROC) curve analysis was used to determine the anti-HBc and anti-HBs cut-off titres for predicting HBV-R. The other predicting factors, namely, serum ALT levels, albumin levels, prothrombin times (\%), total bilirubin levels and age, were each divided into two categories based on their median values. Univariate and multivariate analyses of the factors associated with HBV-R were performed using logistic regression analysis, and factors with $\mathrm{P}$-values $<0.05$ in the univariate analysis were considered in the multivariate model. All statistical analyses were performed using the JMP Pro 11 statistical software package (version 11.2.1, SAS, Cary, NC, USA). All the tests were two-tailed, and $\mathrm{P}<0.05$ was considered to indicate a statistically significant difference.

\section{Results}

Patients (baseline characteristics). Baseline patient clinical characteristics are presented in Table I. The median age of the study population was 75 years (range, 47-89), and diffuse large B-cell lymphoma (DLBCL) was the most common type of lymphoma $(n=53,68.8 \%)$ in the study population. Regarding chemotherapy regimen, 68 patients $(88.3 \%)$ received rituximab-containing chemotherapy. The median length of the follow-up observation period during the study period was 987 days (range, 7-2769) after chemotherapy initiation for lymphoma. Fourteen patients died of lymphoma, and 3 patients died of other diseases.

Of the 77 patients with resolved hepatitis B, 10 (13\%) experienced HBV-R during and after chemotherapy and were subsequently started on oral antiviral agents. Two of these 10 patients developed HBV-related hepatitis flares, but both recovered with treatment, and no patients died of HBV-R. Three of the 10 patients became positive for anti-HBsAg, including 2 patients who developed hepatitis flares.

Impact of the combination of anti-HBc and $\mathrm{HBs}$ titres on predicting $H B V-R$. We performed correlation analyses using HBV-related markers and time to HBV-R (Fig. 2). There was no correlation between anti-HBs titres prior to chemotherapy and time to HBV-R $(R=-0.327, \mathrm{P}=0.357)$ (Fig. $2 \mathrm{~B})$, but anti-HBc titres were significantly negatively correlated with time to HBV-R ( $R=-0.732, \mathrm{P}=0.016)$ (Fig. $2 \mathrm{~A})$. We then established anti-HBs and anti-HBc titre cut-off values for predicting HBV-R via ROC curve analysis of the patients with resolved hepatitis B. Our analysis demonstrated that the anti-HBs and anti-HBc titre cut-off values were $28.5 \mathrm{mIU} / \mathrm{ml}$ (AUC: 0.725 ) and 10.1 S/CO (AUC: 0.616), respectively (Fig. 3A and B). We therefore established anti-HBs and anti-HBc titre cut-off values of $28 \mathrm{mIU} / \mathrm{ml}$ and $10 \mathrm{~S} / \mathrm{CO}$ for predicting HBV-R.

Univariate and multivariate logistic regression analyses were performed to identify the predictive factors associated with HBV-R. In both types of analyses, both anti-HBc and anti-HBs titres at baseline were significant predictive factors for HBV-R. However, rituximab-containing chemotherapy was not a significant predictive factor for HBV-R (Table II). Additionally, treatment efficacy and HBV-R were not correlated (data not shown). 

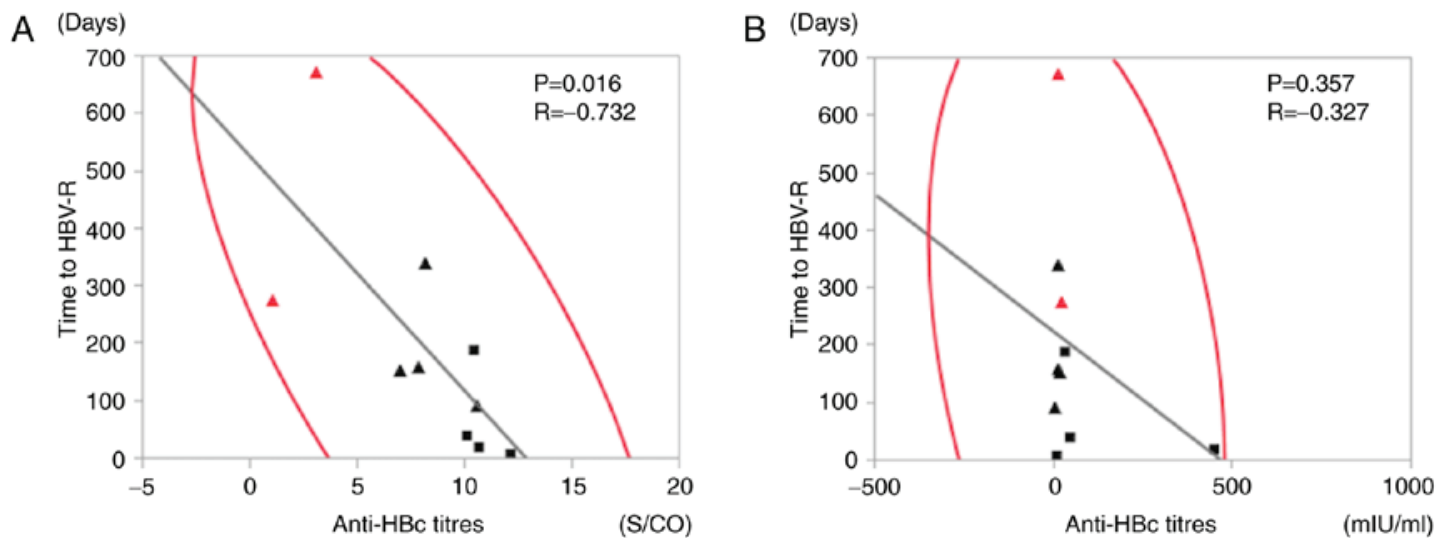

Figure 2. Correlation analysis results of the relationships between time to hepatitis B virus reactivation (HBV-R) and the following HBV-related markers: (A) Anti-hepatitis B core (HBc) titres and (B) anti-hepatitis B surface (HBs) titres. The panels show the correlations between time to HBV-R and the above HBV-related markers $(\mathrm{P}=0.016, R=-0.732$ and $\mathrm{P}=0.357, R=-0.327$, respectively). The solid squares $(\boldsymbol{\bullet})$ and triangles $(\boldsymbol{\Lambda})$ represent patients who experienced HBV-R during chemotherapy and after therapy, respectively. The red marks represent patients who experienced hepatitis flares. The analyses were based on Pearson's correlation coefficient.
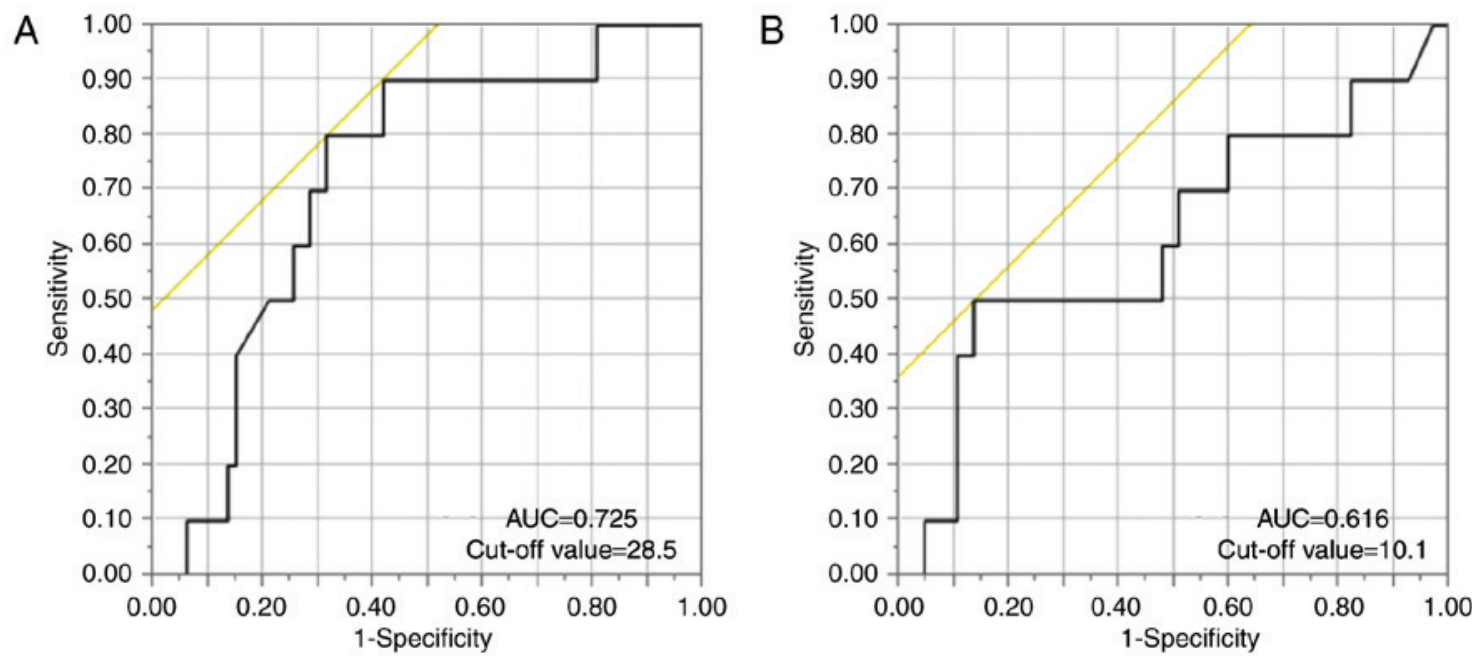

Figure 3. ROC curve analysis of the ability of the cut-off values for (A) anti-hepatitis B surface (HBs) titres and (B) anti-hepatitis B core (HBc) titres to predict hepatitis B virus reactivation (HBV-R) development. The following panels show the HBV-related marker values used to predict HBV-R: (A) AUC=0.725, cut-off value $=28.5$, sensitivity $=0.8$, and specificity $=0.687$; and (B) $\mathrm{AUC}=0.616$, cut-off value $=10.1$, sensitivity $=0.5$, and specificity $=0.876$.

Comparison of $H B V-R$ rates among groups based on anti-HBc and anti-HBs titres. Using the cut-off anti-HBc value alone does not have good predictive value. Therefore, we concluded that the combination of anti-HBc and anti-HBs titres at baseline in patients with lymphoma could serve as a surrogate marker of HBV-R under the influence of chemotherapy. We initially divided the patients with resolved hepatitis B prior to chemotherapy, for whom the combination of anti-HBs and anti-HBc cut-off titres was used to predict HBV-R, into 4 groups. We divided the anti-HBc group into a high-titre group $\left(\mathrm{C}^{\text {high }}\right)$ and a low-titre group $\left(\mathrm{C}^{\text {low }}\right)$ based on the predetermined cut-off levels (Fig. 4A). In the same manner, we divided the anti-HBs group into a high-titre group $\left(S^{\text {high }}\right)$ and a low-titre group $\left(S^{\text {low }}\right)$ (Fig. 4B). However, the $\mathrm{C}^{\text {high }} \mathrm{S}^{\text {high }}(n=9)$ and $\mathrm{C}^{\text {high }} \mathrm{S}^{\text {low }}(n=5)$ groups were analysed collectively as $C^{\text {high }}$ because the number of patients in each group was small and because the incidence of HBV-R (3/9, $33 \% ; 2 / 5,40 \%$, respectively) was high among these patients, resulting in the following $3 \mathrm{HBV}-\mathrm{R}$ risk groups: $\mathrm{C}^{\text {high }}(n=14)$,
$\mathrm{C}^{\text {low }} \mathrm{S}^{\text {low }}(n=23)$ and $\mathrm{C}^{\text {low }} \mathrm{S}^{\text {high }}(n=40)$ (Fig. 4C). Comparison analysis was performed to determine the HBV-R rates in the $\mathrm{C}^{\text {high }}, \mathrm{C}^{\text {low }} \mathrm{S}^{\text {low }}$ and $\mathrm{C}^{\text {low }} \mathrm{S}^{\text {high }}$ groups, which were $35.7 \%$ $(5 / 14), 21.7 \%(5 / 23)$ and $0 \%(0 / 40)$, respectively (Fig. 4C). Consequently, compared with the patients in the $\mathrm{C}^{\text {low }} \mathrm{S}^{\text {high }}$ group, who did not experience complete reactivation, those in the $\mathrm{C}^{\text {high }}$ and $\mathrm{C}^{\text {low }} \mathrm{S}^{\text {low }}$ groups experienced significantly higher rates of HBV-R $(\mathrm{P}<0.0001$ and $\mathrm{P}=0.002$, respectively). Additionally, the patients in the $\mathrm{C}^{\text {high }}$ group experienced a significantly higher rate of HBV-R than those in the $\mathrm{C}^{\text {low }}$ group ( $\mathrm{P}=0.015$; Fig. 4A). Similarly, the patients in the $\mathrm{S}^{\text {low }}$ group experienced a significantly higher rate of HBV-R than those in the $\mathrm{S}^{\text {high }}$ group $(\mathrm{P}=0.031$; Fig. 4B). Additionally, a comparison of the HBV-R rate between those with anti-HBs high and anti-HBs low in the anti-HBc high group $\left(C^{\text {high }} S^{\text {high }}\right.$ vs. $C^{\text {high }} S^{\text {low }}$ ) would be useful for estimating the importance of anti-HBc in HBV-R. Patients in the $\mathrm{C}^{\text {high }} \mathrm{S}^{\text {low }}$ group seemed more likely to experience HBV-R than those in the $\mathrm{C}^{\text {high }} \mathrm{S}^{\text {high }}$ group, although the difference was not statistically significant 
Table II. Analysis of the factors associated with HBV reactivation.

\begin{tabular}{|c|c|c|c|c|}
\hline \multirow[b]{2}{*}{ Variable } & \multicolumn{2}{|c|}{ Univariate analysis } & \multicolumn{2}{|c|}{ Multivariate analysis } \\
\hline & Odds ratio $(95 \% \mathrm{CI})$ & P-value & Odds ratio $(95 \% \mathrm{CI})$ & P-value \\
\hline \multicolumn{5}{|l|}{ Age } \\
\hline$>75$ & 1 & & 1 & \\
\hline$<75$ & $0.914(0.234-3.569)$ & 0.895 & $1.577(0.265-10.693)$ & 0.616 \\
\hline \multicolumn{5}{|l|}{ Sex } \\
\hline M & 1 & & 1 & \\
\hline $\mathrm{F}$ & $0.597(0.121-2.354)$ & 0.471 & $0.425(0.035-4.095)$ & 0.464 \\
\hline \multicolumn{5}{|l|}{ ALT } \\
\hline$>16$ & 1 & & 1 & \\
\hline$<16$ & $1.456(0.381-6.134)$ & 0.583 & $1.986(0.261-16.023)$ & 0.501 \\
\hline \multicolumn{5}{|l|}{ Albumin } \\
\hline$>3.5$ & 1 & & 1 & \\
\hline$<3.5$ & $1.216(0.318-5.127)$ & 0.776 & $1.135(0.182-7.114)$ & 0.889 \\
\hline \multicolumn{5}{|c|}{ Prothrombin time (\%) } \\
\hline$>90$ & 1 & & 1 & \\
\hline$<90$ & $0.853(0.217-3.347)$ & 0.815 & $0.480(0.048-4.046)$ & 0.501 \\
\hline \multicolumn{5}{|c|}{ Total bilirubin } \\
\hline$>0.6$ & 1 & & 1 & \\
\hline$<0.6$ & $2.8(0.711-13.869)$ & 0.144 & $1.733(0.266-12.171)$ & 0.560 \\
\hline \multicolumn{5}{|c|}{ Anti-HBc titres (S/CO) } \\
\hline$>10$ & 1 & & 1 & \\
\hline$<10$ & $0.115(0.036-0.655)$ & 0.012 & $0.110(0.013-0.665)$ & 0.016 \\
\hline \multicolumn{5}{|c|}{ Anti-HBs titres (mIU/ml) } \\
\hline$>28$ & 1 & & 1 & \\
\hline$<28$ & $5.111(1.286-25.565)$ & 0.020 & $10.505(1.749-105.993)$ & 0.009 \\
\hline \multicolumn{5}{|c|}{ Treatment regimen } \\
\hline RTX(+) & 1 & & 1 & \\
\hline RTX(-) & $1.579(0.253-30.717)$ & 0.665 & $1.331(0.120-34.000)$ & 0.828 \\
\hline
\end{tabular}

Age, sex, ALT, Alb, PT (\%) and T-Bil are expressed as median values. Anti-HBc and anti-HBs titres were identified by ROC curve analysis. 95\% CI, 95\% confidence interval; ALT, alanine aminotransferase; HBc, hepatitis B core; HBs, hepatitis B surface; M, male; F, female; RTX, rituximab.

due to the limited number of subjects. An overview of the 4 groups categorized by antibody titres is provided in Table III.

Comparison of time to $H B V-R$ after starting chemotherapy among the three groups. No patients in the $C^{\text {low }} S^{\text {high }}$ group completely reactivated. Therefore, the median time to HBV-R after starting chemotherapy was compared between the $\mathrm{C}^{\text {high }}$ and $\mathrm{C}^{\text {low }} \mathrm{S}^{\text {low }}$ groups via the log-rank test. Their cumulative median times were 41 and 277 days (range, 9-190, 156-673), respectively. In the $\mathrm{C}^{\text {high }}$ group, all cases of HBV-R occurred within 1 year after starting chemotherapy $(\mathrm{P}<0.0001)$. However, in the $\mathrm{C}^{\text {low }} \mathrm{S}^{\text {low }}$ group, one patient (1/5) developed HBV-R beyond 1 year after starting or finishing chemotherapy (673 or 475 days, respectively) (Fig. 5).

Details of the 10 patients who developed $H B V-R$. The details of the 10 patients who developed HBV-R are shown in Table IV, which lists these patients' $\mathrm{HBcAb}$ titres prior to chemotherapy in descending order. Of these 10 patients, 7 (70\%) were male. The patients with HBV-R ranged from 62-82 years of age. Two patients $(20 \%)$ developed HBV-related hepatitis flares, and three patients' (30\%) serum HBsAg turned positive after HBV-R. Both patients with hepatitis flares experienced a reversion of their HBsAg seropositivity.

Regarding the clinical courses of the patients with HBV-R, the median anti-HBc titres and anti-HBs titres prior to chemotherapy were $9.1 \mathrm{~S} / \mathrm{CO}$ and $13.6 \mathrm{mIU} / \mathrm{ml}$, respectively. The median time from the start of chemotherapy to HBV-R in the four patients who experienced reactivation during chemotherapy was 31 days (range, 9-190), and all these patients were in the $\mathrm{C}^{\text {high }}$ group. In contrast, the median time to HBV-R in the six patients who experienced reactivation during follow-up was 91 days (range, 1-475) from the final chemotherapy treatment to HBV-R. Three of the 10 patients had delayed HBV-R 
$\mathrm{A}_{(\%)}$

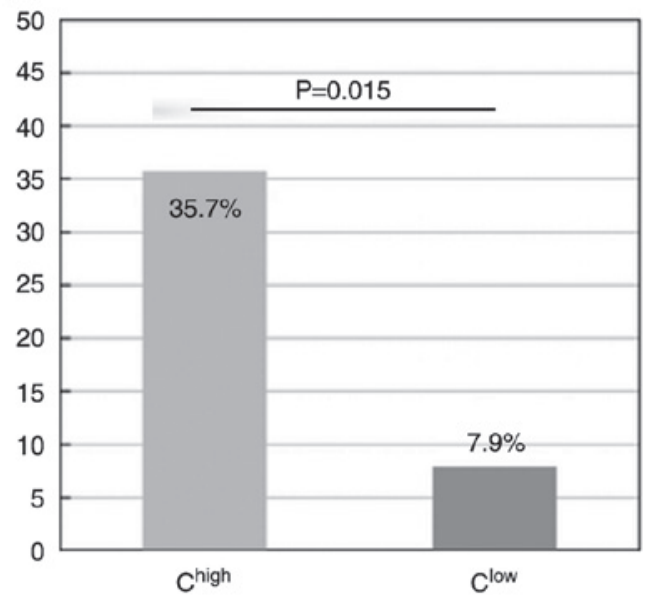

B (\%)

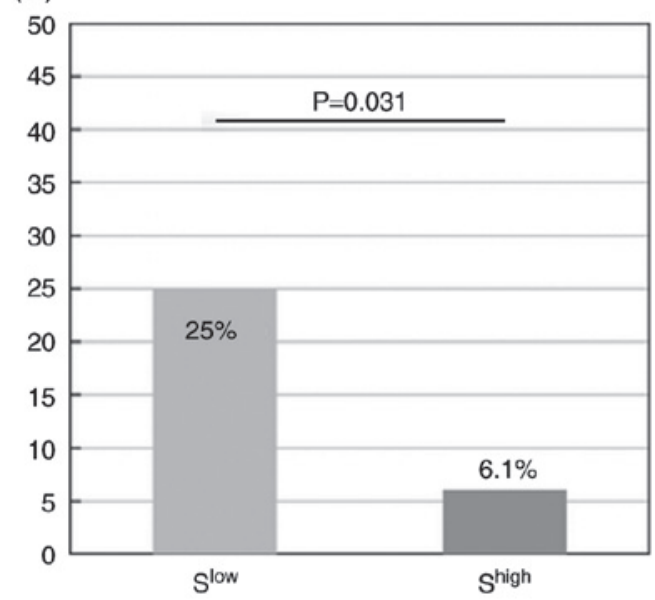

C (\%)

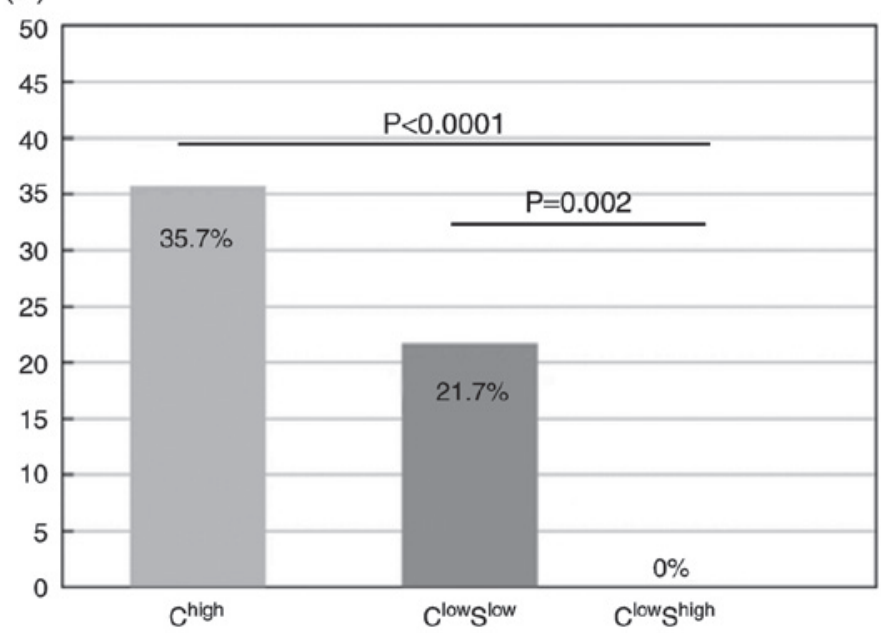

Figure 4. Incidence of hepatitis B virus reactivation (HBV-R). (A) Lymphoma patients were divided into the following two groups according to cut-off values predetermined via ROC analysis: A high anti-hepatitis B core $(\mathrm{HBc})(\mathrm{HBc})$ titre group $\left(\mathrm{C}^{\text {high }}\right)$ and a low anti- $\mathrm{HBc}\left(\mathrm{C}^{\text {low }}\right)$ group. The left and right bars represent the data for the $\mathrm{C}^{\text {high }}$ and $\mathrm{C}^{\text {low }}$ groups, respectively. The incidences of HBV-R in the two groups are shown $\left(\mathrm{C}^{\text {high }}=35.7 \%(5 / 14)\right.$ and $\mathrm{C}^{\text {low }}=7.9 \%(5 / 63)$, respectively). The $\mathrm{C}^{\text {high }}$ group experienced a significantly higher rate of HBV-R than the $\mathrm{C}^{\text {low }}$ group $(\mathrm{P}=0.015)$. The incidences of HBV-R were compared using Chi-square tests. (B) Lymphoma patients were divided into the following two groups according to cut-off values predetermined via ROC curve analysis of anti-hepatitis B surfac(HBs) titres: A high anti-HBs titre group ( $\left.\mathrm{S}^{\text {high }}\right)$ and a low anti-HBs group $\left(\mathrm{S}^{\text {low }}\right)$. The left and right bars show the data for $\mathrm{S}^{\text {low }}$ and $\mathrm{S}^{\text {high }}$, respectively. The incidences of HBV-R in the two groups are shown $\left(\mathrm{S}^{\mathrm{low}}=25 \%(7 / 28)\right.$ and $\mathrm{S}^{\text {high }}=6.1 \%(3 / 49)$, respectively). The $\mathrm{S}^{\text {low }}$ group experienced a significantly higher rate of HBV-R than the $S^{\text {high }}$ group $(\mathrm{P}=0.031)$. The incidences of HBV-R were compared using chi-square tests. (C) Lymphoma patients were divided into the following three groups according to cut-off values predetermined via ROC analysis: A high anti-HBc titre group (C $\left.\mathrm{C}^{\text {high }}\right)$, a low anti-HBc/low anti-HBs (C ${ }^{\text {low }} \mathrm{S}^{\text {low }}$ ) group, and a $\mathrm{C}^{\text {low }} /$ high anti-HBs titre group $\left(\mathrm{C}^{\text {low }} \mathrm{S}^{\text {high }}\right)$. The left, middle and right bars represent the data for the $\mathrm{C}^{\text {high }}, \mathrm{C}^{\text {low }} \mathrm{S}^{\text {low }}$ and $\mathrm{C}^{\text {low }} \mathrm{S}^{\text {high }}$ groups, respectively. The incidences of HBV-R in the three groups are shown $\left(C^{\text {high }}=35.7 \%(5 / 14), C^{\text {low }} S^{\text {low }}=21.7 \%(5 / 23)\right.$, and $C^{\text {low }} S^{\text {high }}=0 \%(0 / 40)$, respectively). $C^{\text {high }}$ and $C^{\text {low }} S^{\text {low }}$ experienced a significantly higher rate of HBV-R than did $\mathrm{C}^{\text {low }} \mathrm{S}^{\text {high }}, \mathrm{P}<0.0001$ and $\mathrm{P}=0.002$, respectively. The incidences of HBV-R were compared using the Kruskal-Wallis non-parametric test.

$(30 \%)$, and all three were in the $\mathrm{C}^{\text {low }} \mathrm{S}^{\text {low }}$ group. No cases of HBV-related fulminant hepatitis or hepatitis-related deaths occurred during the study period. All 5 patients with HBV-R and lower titres of HBcAb showed lower titres of HBsAb (Table IV). Thus, patients in the $\mathrm{C}^{\mathrm{low}} \mathrm{S}^{\text {high }}$ group did not experience complete reactivation, but those in the $\mathrm{C}^{\text {low }} \mathrm{S}^{\text {low }}$ group had a relatively higher risk of HBV-R.

\section{Discussion}

Fatal HBV-R is a well-described serious complication of chemotherapy in cancer patients with resolved HBV infection and is reported to have a higher incidence than liver-related mortality in patients with acute hepatitis (13). Meticulous monitoring of HBV DNA is a unique predictive method of detecting the occurrence of life-threatening HBV-R $(9,10)$. Thus far, the patterns that are predictive of the occurrence of HBV-R remain unclear, and methods for identifying these patterns are in high demand clinically and economically.

The relationship between HBV-R and HBV-related markers in lymphoma patients with resolved HBV infection has recently been reported.In previous reports related to anti-HBs, lymphoma patients with high anti-HBs titres $(>100 \mathrm{mIU} / \mathrm{ml})$ prior to chemotherapy experienced significantly lower HBV-R rates than did other patients (7). However, patients with undetectable anti-HBs titres $(<10 \mathrm{mIU} / \mathrm{ml})$ faced a significantly higher risk of HBV-R than did other patients and had a poor prognosis $(9,14)$. Regarding anti-HBc, anti-HBc-positive patients were reported 
Table III. Details of the 4 groups categorized by antibody titres.

\begin{tabular}{|c|c|c|c|c|c|c|c|c|}
\hline Group & Patients, n & Age, years & $\begin{array}{c}\text { Sex } \\
(\% \text { male })\end{array}$ & $\begin{array}{l}\text { Anti-HBc } \\
\text { titres }(\mathrm{S} / \mathrm{CO})\end{array}$ & $\begin{array}{l}\text { Anti-HBs } \\
\text { titres }(\mathrm{mIU} / \mathrm{ml})\end{array}$ & $\begin{array}{l}\text { Occurrence of } \\
\text { HBV-R }(\%)\end{array}$ & $\begin{array}{c}\text { Time to } \\
\text { HBV-R (days) }\end{array}$ & HBV-R/HF \\
\hline $\mathrm{C}^{\text {high }} \mathrm{S}^{\text {high }}$ & 9 & $76(71-83)$ & 56 & $10.8(10.1-12.9)$ & $254(28.5-500)$ & 33.3 & $84(21-190)$ & HBV-R \\
\hline $\mathrm{C}^{\text {high }} \mathrm{S}^{\text {low }}$ & 5 & $78(73-81)$ & 60 & $16.2(10.6-35)$ & $3.5(0-6.7)$ & 40 & $51(9-93)$ & HBV-R \\
\hline $\mathrm{C}^{\text {low }} \mathrm{S}^{\text {high }}$ & 40 & $73(47-89)$ & 60 & $6.1(0.07-10)$ & $358(28.6-2990)$ & 0 & none & HBV-R \\
\hline $\mathrm{C}^{\text {low }} \mathrm{S}^{\text {low }}$ & 23 & $76(62-83)$ & 61 & $6.4(0.98-9.85)$ & $10.9(0.2-27.5)$ & 21.7 & $322(156-673)$ & HBV-R/HF \\
\hline
\end{tabular}

$\mathrm{C}^{\text {high }} \mathrm{S}^{\text {high }}$, high anti-HBc titres and high anti-HBs titres; $\mathrm{C}^{\text {high }} \mathrm{S}^{\text {low }}$, high anti-HBc titres and low anti-HBs titres; $\mathrm{C}^{\text {low }} \mathrm{S}^{\text {high }}$, low anti-HBc titres and high anti-HBs titres; $\mathrm{C}^{\text {low }} \mathrm{S}^{\text {low }}$, low anti-HBc titres and low anti-HBs titres. HBc, hepatitis B core; HBs, hepatitis B surface; HBV-R, hepatitis B virus reactivation; HF, hepatitis flare. Age; sex; anti-HBc titres; anti-HBs titres and time to HBV-R indicate average values.
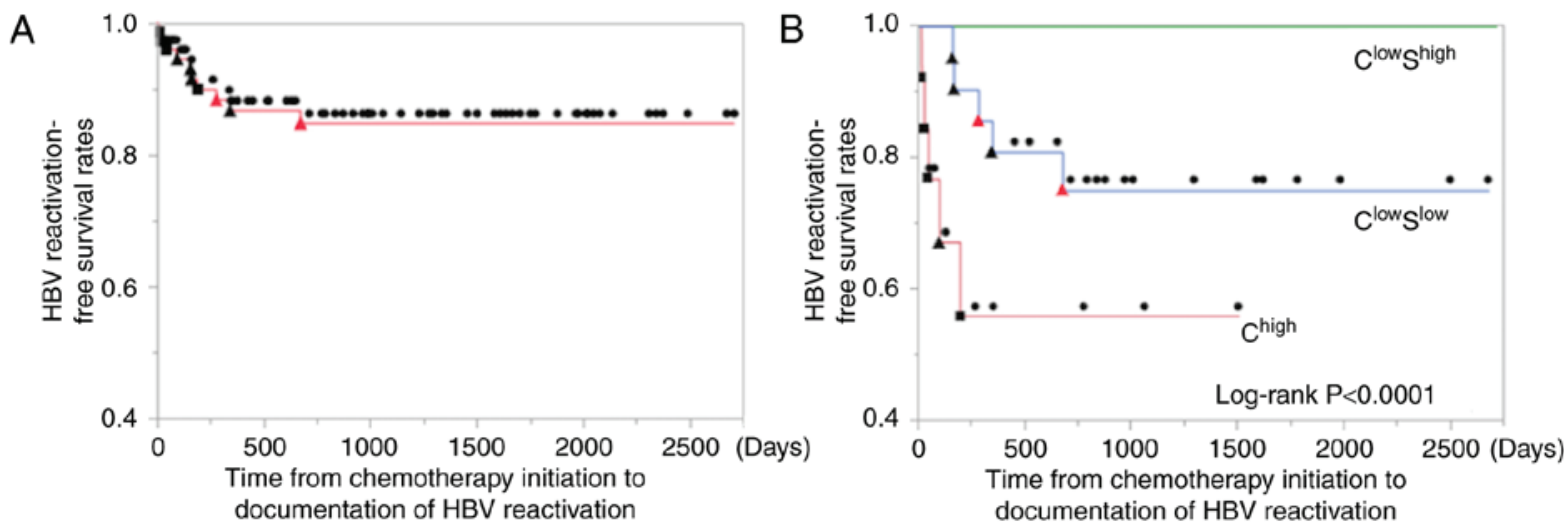

Figure 5. Analysis of time to hepatitis B virus reactivation (HBV-R) using the Kaplan-Meier method. The log-rank test was used for comparisons. (A) The left panel shows the time to HBV-R in all patients. (B) The right panel shows the time to HBV-R in each of the three groups. The closed square and triangle marks represent those patients who experienced HBV-R during chemotherapy (⿶) and after therapy ( $\mathbf{\Lambda})$, respectively. The closed circle marks represent no HBV-R $(\bullet)$. The red marks represent the patients who experienced hepatitis flare. The $\mathrm{C}^{\text {high }}$ group experienced a significantly shorter time to HBV-R than did the $\mathrm{C}^{\text {low }} \mathrm{S}^{\text {high }}$ group, $\mathrm{P}<0.0001$.

to experience reactivation rates that were significantly higher than those of anti-HBc-negative patients (15). The results of these previous reports indicate that the incidence of HBV-R may be associated with the HBV immune status of the host prior to therapy. Hence, we retrospectively examined the risk factors for developing HBV-R using data pertaining to HBV-related markers in patients with resolved $\mathrm{HBV}$ infection. In the present study, we found that the combination of anti-HBc and anti-HBs levels may be useful for predicting the development and timing of chemotherapy-induced hepatitis B reactivation in lymphoma patients with resolved HBV infection. Our results demonstrated that patients with high anti-HBc titres (>10 S/CO) prior to chemotherapy experienced a significantly higher rate of HBV-R than did patients with both low anti-HBc $(<10 \mathrm{~S} / \mathrm{CO})$ and high anti-HBs levels ( $>28 \mathrm{mIU} / \mathrm{ml})$, who did not completely reactivate. We conclude that anti-HBc and anti-HBs titres prior to chemotherapy can be used to identify HBV-R in lymphoma patients with resolved HBV infection. We did not track serial changes in these parameters because regular monitoring of only $\mathrm{HBV}-\mathrm{DNA}$, not of $\mathrm{HBsAg}, \mathrm{HBcAb}$ or $\mathrm{HBsAb}$, is recommended according to the guidelines (12). However, we agree that monitoring serial changes in $\mathrm{HBsAg}, \mathrm{HBcAb}$ and $\mathrm{HBsAb}$ during the follow-up period is important, and this will be done in future studies.
Generally, anti-HBc antibodies are considered an indicator of past and persistent HBV infection. However, it is well-recognized that the utility of quantitative anti-HBc (qAnti-HBc) measurements is hampered by detection technology limitations and a lack of international standardization compared with measurements of anti-HBs. Additionally, to date, little is known about the clinical significance of qAnti-HBc levels; however, several recent reports revealed that baseline qAnti-HBc levels were a useful predictor of treatment response in both interferon-alpha and nucleoside analogue therapy. Additionally, qAnti-HBc levels were closely correlated with signs of hepatic inflammation, such as ALT levels, during therapy and follow-up. The reported mechanism behind this correlation involves the release of $\mathrm{HBcAg}$ particles from damaged hepatocytes and the production of antibodies against $\mathrm{HBcAg}$ by B-cells, resulting in increased serum anti-HBc levels $(16,17)$. These results indicate that higher qAnti-HBc levels at baseline may reflect higher host immune activity for $\mathrm{HBV}$. The reason for the discrepancy between anti-HBc and anti-HBs levels in the host immune response against HBV remains unclear, but Zhang et al (16) reported a difference in the intrahepatic localization of $\mathrm{HBcAg}$ and $\mathrm{HBAg}$, which may provide insight into the observed discrepancy in levels. In the present study, the same method of measuring qAnti-HBc 


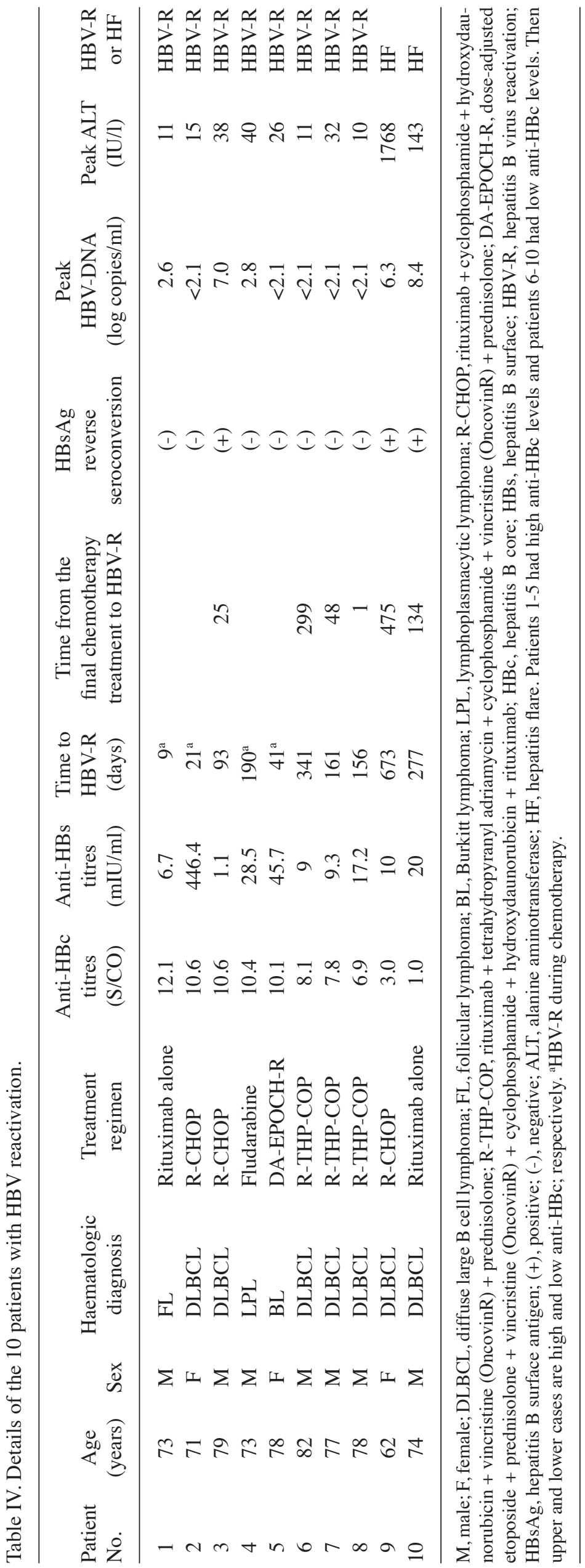


levels was used throughout the study period. Regarding the incidence of $\mathrm{HBV}-\mathrm{R}$, we speculate that patients with high anti-HBc titres can regularly activate their immunity for $\mathrm{HBV}$; therefore, they may be much more likely to experience HBV-R when host immunity is supressed by chemotherapy or immunosuppressive treatment. However, clinical evidence regarding the ability of qAnti-HBc to predict HBV-R is lacking, and the collection of additional data is awaited.

In patients with resolved HBV infection, HBV replication has been shown to persist in the liver and in peripheral blood mononuclear cells for decades $(17,18)$. Interestingly, in healthy liver transplantation donors with anti-HBc-positivity, HBsAg-negativity and undetectable HBV DNA, HBV was shown to be present in the liver, resulting in HBV-R in recipients due to transmission after transplantation (19). These reports show that even patients previously infected with HBV who were considered to be cured of clinical infection retain $\mathrm{HBV}$ in their bodies, resulting in a risk of HBV-R during and after chemotherapy and immunosuppressive treatment.

To date, several studies of host immune status after acute hepatitis have been performed. These studies have reported that insufficient decreases in anti-HBc titres after acute hepatitis B infection may influence the disappearance of HBV DNA $(20,21)$. Therefore, the existence of a relationship between HBV-R and declining immunocompetence in patients with resolved HBV infection cannot be denied. Thus, circulating HBV antigen-antibody marker measurements are very important for understanding the immune condition of the host after HBV infection. Furthermore, these reports indicate that the levels of HBV-related antibodies, including anti-HBc and anti-HBs, may serve as surrogate markers for host anti-HBV immune status after acute hepatitis B infection. Based on these reports, we examined whether anti-HBc and anti-HBs titres at baseline prior to chemotherapy were related to the development and timing of HBV-R in lymphoma patients with resolved $\mathrm{HBV}$ infection. In a previous study of HBV-R and timing in HBsAg-negative patients who underwent cytotoxic chemotherapy, Hui et al (4) reported that the time to HBV-R, defined as a 100-fold increase in serum HBV-DNA levels compared with pre-therapy levels, was 18.5 weeks after starting chemotherapy (range, 12 to 28 weeks). Additionally, a multicentre cooperative study in Japan reported that $36 \%$ of patients who experienced HBV-R developed reactivation more than 12 months after completion of chemotherapy (22). However, it has been difficult to predict the incidence and timing of HBV-R prior to therapy. In this study, we investigated whether HBV-related markers can predict the development of HBV-R.

Our study has several limitations because of its retrospective design. Although the criteria and monitoring of HBV-R have been introduced according to the Hepatitis B Treatment Guidelines of the Japan Society of Hepatology since 2011 in Japan, they are not based on conclusive evidence. Consequently, in the present study, the follow-up strategy, including the administration of HBV DNA tests or the evaluation of anti-HBc or anti-HBs status prior to chemotherapy, was determined by the attending physicians. This suggests that HBV DNA monitoring may be necessary every one to three months and that we might have underestimated the incidence of self-limited HBV-R. However, no deaths due to HBV-R occurred during the approximately 2.7-year follow-up period. Therefore, it is economically important to identify those patients at high risk for HBV-R and the factors associated with its timing. This study was conducted in only lymphoma patients. Accordingly, it is possible that the results could be applied to patients with other malignancies, but there are no data at this time on the diagnostic value of our findings in other patient populations.

In summary, the combination of anti-HBc and anti-HBs titres may represent a predictive marker for the development of HBV-R and can reflect the elapsed time between chemotherapy initiation and HBV-R. Because this retrospective cohort study was performed at a single centre, validation analyses with a prospective cohort in a clinical study group or at a high-volume centre should be performed to confirm these findings.

\section{Acknowledgements}

The authors would like to thank Dr Hironori Take for assistance with data collection and Dr Tatsuya Kanto for their advice and comments during the preparation of the manuscript.

\section{References}

1. Huang YH, Hsiao LT, Hong YC, Chiou TJ, Yu YB, Gau JP, Liu CY, Yang MH, Tzeng CH, Lee PC, et al: Randomized controlled trial of entecavir prophylaxis for rituximab-associated hepatitis $\mathrm{B}$ virus reactivation in patients with lymphoma and resolved hepatitis B. J Clin Oncol 31: 2765-2772, 2013.

2. Matsue K, Kimura S, Takanashi Y, Iwama K, Fujiwara H, Yamakura $M$ and Takeuchi M: Reactivation of hepatitis B virus after rituximab-containing treatment in patients with CD20-positive B-cell lymphoma. Cancer 116: 4769-4776, 2010.

3. Yeo W, Chan TC, Leung NW, Lam WY, Mo FK, Chu MT, Chan HL, Hui EP, Lei KI, Mok TS and Chan PK: Hepatitis B virus reactivation in lymphoma patients with prior resolved hepatitis B undergoing anticancer therapy with or without rituximab. J Clin Oncol 27: 605-611, 2009.

4. Hui CK, Cheung WW, Zhang HY, Au WY, Yueng YH, Leung AY, Leung N, Luk JM, Lie AK, Kwong YL, et al: Kinetics and risk of de novo hepatitis B infection in HBsAg-negative patients undergoing cytotoxic chemotherapy. Gastroenterology 131: 59-68, 2006 .

5. Fukushima N, Mizuta T, Tanaka M, Yokoo M, Ide M, Hisatomi T, Kuwahara N, Tomimasu R, Tsuneyoshi N, Funai N and Sueoka E: Retrospective and prospective studies of hepatitis $\mathrm{B}$ virus reactivation in malignant lymphoma with occult HBV carrier. Ann Oncol 20: 2013-2017, 2009 .

6. Dong HJ, Ni LN, Sheng GF, Song HL, Xu JZ and Ling Y: Risk of hepatitis $\mathrm{B}$ virus (HBV) reactivation in non-Hodgkin lymphoma patients receiving rituximab-chemotherapy: A meta-analysis. J Clin Virol 57: 209-214, 2013.

7. Cho Y, Yu SJ, Cho EJ, Lee JH, Kim TM, Heo DS, Kim YJ and Yoon JH: High titers of anti-HBs prevent rituximab-related viral reactivation in resolved hepatitis B patient with non-Hodgkin's lymphoma. J Med Virol 88: 1010-1017, 2016.

8. Hayashi K, Ishigami M, Ishizu Y, Kuzuya T, Honda T, Tachi Y, Ishikawa T, Katano Y, Yoshioka K, Toyoda H, et al: Clinical characteristics and molecular analysis of hepatitis $\mathrm{B}$ virus reactivation in hepatitis $B$ surface antigen-negative patients during or after immunosuppressive or cytotoxic chemotherapy. J Gastroenterol 51: 1081-1089, 2016.

9. Seto WK, Chan TS, Hwang YY, Wong DK, Fung J, Liu KS, Gill H, Lam YF, Lie AK, Lai CL, et al: Hepatitis B reactivation in patients with previous hepatitis B virus exposure undergoing rituximab-containing chemotherapy for lymphoma: A prospective study. J Clin Oncol 32: 3736-3743, 2014.

10. Kusumoto S, Tanaka Y, Suzuki R, Watanabe T, Nakata M, Takasaki H, Fukushima N, Fukushima T, Moriuchi Y, Itoh K, et al: Monitoring of hepatitis B virus (HBV) DNA and risk of $\mathrm{HBV}$ reactivation in $\mathrm{B}$-cell lymphoma: A prospective observational study. Clin Infect Dis 61: 719-729, 2015. 
11. Nishida T, Hiramatsu N, Mizuki M, Nagatomo I, Kida H, Tazumi K, Shinzaki S, Miyazaki M, Yakushijin T, Tatsumi T, et al: Managing hepatitis B virus carriers with systemic chemotherapy or biologic therapy in the outpatient clinic. Hepatol Res 43: 339-346, 2013.

12. Drafting Committee for Hepatitis Management Guidelines and the Japan Society of Hepatology: JSH Guidelines for the Management of Hepatitis B Virus infection. Hepatol Res 44 (Suppl): S1-S58, 2014

13. Umemura T, Tanaka E, Kiyosawa $\mathrm{K}$ and Kumada H; Japan de novo Hepatitis B Research Group: Mortality secondary to fulminant hepatic failure in patients with prior resolution of hepatitis B virus infection in Japan. Clin Infect Dis 47: e52-e56, 2008.

14. Pei SN, Ma MC, Wang MC, Kuo CY, Rau KM, Su CY and Chen CH: Analysis of hepatitis B surface antibody titers in B cel lymphoma patients after rituximab therapy. Ann Hematol 91: 1007-1012, 2012.

15. Han JW, Yang H, Lee HL, Bae SH, Choi JY, Lee JW, Kim HJ, Lee S, Cho SG, Min CK, et al: Risk factors and outcomes of hepatitis B virus reactivation in hepatitis B surface antigen negative patients with hematological malignancies. Hepatol Res 46: 657-668, 2016

16. Zhang X, Lu W, Zheng Y, Wang W, Bai L, Chen L, Feng Y, Zhang $\mathrm{Z}$ and Yuan Z: In situ analysis of intrahepatic virological events in chronic hepatitis B virus infection. J Clin Invest 126 : 1079-1092, 2016.

17. Rehermann B, Ferrari C, Pasquinelli C and Chisari FV: The hepatitis $\mathrm{B}$ virus persists for decades after patients' recovery from acute viral hepatitis despite active maintenance of a cytotoxic T-lymphocyte response. Nat Med 2: 1104-1108, 1996.
18. Yuki N, Nagaoka T, Yamashiro M, Mochizuki K, Kaneko A, Yamamoto K, Omura M, Hikiji K and Kato M: Long-term histologic and virologic outcomes of acute self-limited hepatitis B. Hepatology 37: 1172-1179, 2003.

19. Uemoto S, Sugiyama K, Marusawa H, Inomata Y, Asonuma K, Egawa $\mathrm{H}$, Kiuchi T, Miyake $\mathrm{Y}$, Tanaka $\mathrm{K}$ and Chiba $\mathrm{T}$ : Transmission of hepatitis B virus from hepatitis B core antibody-positive donors in living related liver transplants. Transplantation 65: 494-499, 1998.

20. Akahane Y, Okada S, Sakamoto M, Wakamiya M, Kitamura T, Tawara A, Naitoh S, Tsuda F and Okamoto H: Persistence of hepatitis B viremia after recovery from acute hepatitis B: Correlation between anti-HBc titer and HBV DNA in serum. Hepatol Res 24: 8, 2002.

21. Kobyashi M, Chayama K, Arase Y, Tsubota A, Saitoh S, Suzuki Y, Kobayashi M, Murashima N, Ikeda K, Hagiwara M, et al: Progressive and sufficient decrease of hepatitis B core antibody can predict the disappearance of hepatitis B virus DNA in Japanese patients with hepatitis B surface antigen clearance. J Gastroenterol 35: 753-757, 2000.

22. Takahashi H, Ikeda M, Kumada T, Osaki Y, Kondo S, Kusumoto S, Ohkawa K, Nadano S, Furuse J, Kudo M, et al: Multicenter cooperative case survey of hepatitis B virus reactivation by chemotherapeutic agents. Hepatol Res 45: 1220-1227, 2015. 